Cuad. invest. hist. Brocar n. 17 (1991). Págs. 21-36.

\title{
LA MASONERÍA DE OBEDIENCIA ESPAÑOLA ANTE EL CONFLICTO COLONIAL PUERTORRIQUEÑO
}

\author{
José Antonio Ayala*
}

\begin{abstract}
RESUMEN.-Se trata de analizar el papel jugado por la masoneria de obediencia española en el contexto general de la Isla de Puerto Rico, ya que no se puede olvidar el influjo ideológico de varias masonerias en esta isla del Caribe y que se dejó percibir desde los primeros años delsiglo XIX. De todas las formas, 1871 fue elmomento clave en que la Ordendeja de ser clandestina para, trasser legalizada y tolerada, deje notar la implantación de determinadas ideas. Su separación de España se debió a la intervención de los Estados Unidos y no a ninguna otra influencia ni masónica, ni no masónica.
\end{abstract}

SUMMARY.- The Masonry Subject to Spanish Obedience before the Colonial Conflict at Puerto Rico. This paper is intended to the analysis of the role played by Spanish Masonry in the general context of the Island of Puerto Rico since the ideological influence-already perceptible in the first years of the XIX th centuryexerted by several masoneries cannot be forgotten. In any case 1871 was the keyyear in which Order, after being legalized-eith the consequent abandonment of clandestinity and the new situation of tolerance-started showing certain purposes. The independence from Spain was due to the intervention of the U.S.A and in no case to other masonic ofnon-masonic influences.

Palabras clave: Masonería, Obediencia española, Puerto Rico, Conflicto colonial, Separación.

Key words: Masonry Spanish obedience, Puerto Rico, Colonial conflict, Independence.

Aunque el título de esta ponencia es lo suficientemente específico no está de más que desde el principio delimitemos el ámbito de la investigación realizada y el relativo papel

\footnotetext{
${ }^{*}$ Universidad de Murcia.
} 


\section{JOSE ANTONIO AYALA}

jugado por la masonería que consideramos -la de obediencia española- en el contexto general puertorriqueño.

Podemos distinguir el influjo ideológico de varias masonerías en Puerto Rico desde que en los primeros años del siglo XIX esta asociación penetró en la isla caribeña. Cronológicamente, el año 1871, la época pues del «sexenio revolucionario», como ocurrió en la Península, fue el hito que marcó dos épocas, caracterizada la primera, anterior a este año, por la clandestinidad o semiclandestinidad y la dispersión de obediencias, y caracterizada la segunda, desde 1871 a 1898, por la tolerancia o legalización, la expansión de la Orden y la permanente implantación de determinadas obediencias.

A principios del siglo XIX comenzó la difusión de las ideas masónicas en Puerto Rico de la mano de emigrantes franceses procedentes de Haití, debido a los sucesos revolucionarios que aquejaron aquel territorio. Hubo logias establecidas, al parecer, en San Juan, Ponce y San Germán. Desde 1814 cesa, sin embargo, toda actividad masónica hasta el trienio liberal, en que hay noticia de una primera logia cuya denominación es conocida - La Fortaleza- relacionada al parecer con la masonería cubana ${ }^{1}$.

En los años posteriores, hasta principios de los años cuarenta, dos influjos masónicos intermitentes se hicieron sentir en la isla: el norteamericano, en ocasiones vía Cuba, y el francés vía Santo Domingo, fundador este último de una serie de organismos denominados todos Restauración de la Verdad ${ }^{2}$. Desde aquel año hasta la Revolución en Lares, en 1868, de nuevo se hizo patente la influencia de otros Orientes del área, en concreto el dominicano y el venezolano. Fueron casi todos los organismos fundados en esta época bastante efímeros y su existencia está poco documentada, a excepción de los franceses entre 1821 y 1841 , de los que se conserva una regular documentación en la Biblioteca Nacional de París.

El segundo período de la masonería puertorriqueña se inició en 1871 con la fundación por el Gran Oriente Nacional de España de tres logias en San Juan, Ponce y Mayagüez. Al parecer, según noticias posteriores, siete puertorriqueños fueron iniciados en la logia madrileña Los Puritanos $n .^{\circ} 13$ y fueron ellos los que a su vez iniciaron a los componentes de esos tres primeros núcleos ${ }^{3}$.

En 1871 se inició, pues, la penetración de las obediencias españolas en Puerto Rico, como después ampliaremos; pero la difusión de estas estuvo siempre contestada, hasta 1898, por una masonería autodefinida como autóctona, procedente de Cuba, con la que compitió a lo largo de esos años. Como esta masonería es la que no hemos estudiado en nuestro trabajo, vamos a dar aquí los rasgos más sobresalientes y generales de la misma como elemento de contraste de la exposición posterior ${ }^{4}$.

La masonería de origen cubano-norteamericana es anterior a la propiamente española. Se remonta a diciembre de 1858 , mes y año en que tres logias de Santiago de Cuba auspiciadas por la Gran Logia de Carolina del Sur, en Estados Unidos, con sede en Charleston, consiguieron que se les reconociese el establecimiento de la denominada

\footnotetext{
1 Archivo General de Palacio. Madrid. Papeles Reservados de Fernando VII, t. 87, fol. 203 v.

2 Biblioteca Nacional de París, sección de manuscritos, fondo Francmasonería, leg. FM2.543.

3 «Boletín Oficial y Revista Masónica de la Gran Logia Regional de Puerto Rico», n.o 12, 30-11-1913.

4 Archivo Histótico Nacional de Salamanca-desde ahora AHNS-, sec. Masonería, leg. 736 A, exp. 5.
} 
Gran Logia de Colón, y al poco, un Supremo Consejo de Colón en Santiago de Cuba, con jurisdicción en todas las Indias Occidentales, incluida, claro está, Puerto Rico.

En los años siguientes, hasta la revoluciones de 1868, esta jurisdicción de la cubana fue meramente nominal por lo que respecta a Puerto Rico: sólo una logia se fundó en esta isla durante la década, la Estrella de Luquillo n. $^{-17}$, en Bayamón, ya en el tardío año de 1867 y por unos pocos meses; ninguna otra potencia masónica respetó el supuesto derecho de Cuba sobre el territorio puertorriqueño ni en los altos organismos masónicos cubanos existía representación alguna de la filial puertorriqueña. Hasta 1871 no comienza Santiago Rosendo Palmer, considerado como el «padre de la masonería autóctona», a fundar las primeras logias puertorriqueñas, desvinculadas al principio de toda obediencia y muy efímeras. En 1878 estas primeras logias se pusieron bajo los auspicios de la Gran Logia Unida de Colón, en Cuba, y la amistad de Palmer con el gran secretario de este organismo, Aurelio Almeida, le valió su nombramiento como diputado gran maestro de distrito para toda la isla de Puerto Rico.

En el entreacto, se había producido un acontecimiento internacional de importancia que va a afectar a las islas caribeñas: la celebración en 1875 del Congreso Masónico Internacional de Lausana (Suiza). Fue un Congreso este minoritario, en el que sólo estuvieron representados 22 Supremos Consejos del Grado 33 y al que no asistieron las obediencias españolas. El Gran Consejo de Colón, que ostentó la presidencia, contó con el apoyo de dos grandes consejos de Estados Unidos, sus mentores de otro tiempo, y de otros paises hispanoamericanos (Costa Rica, Chile, Colombia, Argentina, Méjico, etc.) para hacer triunfar su autonomía de la metrópoli: el Congreso acordó que los territorios masónicos de Cuba y Puerto Rico pasaban a depender del Supremo Consejo de Colón, aunque políticamente siguieran dependiendo de España.

Las primeras logias puertorriqueñas, pues, posteriores a 1871 , al ponerse bajo la obediencia cubana se beneficiaron de este reconocimiento internacional, y frente a las logias de obediencia española esgrimirán su derecho a existir y su autonomía de la metrópoli en base a aquel Congreso.

La expansión de esta masonería autóctona, o semiautóctona, puertorriqueña fue bastante rápida. Entre 1878 y 1884 se fundaron siete logias, número que hacía factible la creación de una gran logia independiente en Puerto Rico. En efecto, en octubre de ese último año, Palmer solicitaba a la Gran Logia Unida de Cuba el permiso para fundar su propia Gran Logia Provincial de Puerto Rico, y obtenida la sanción correspondiente dicho organismo quedó instalado al poco tiempo en la ciudad de Mayagüez.

La Gran Logia Provincial de Puerto Rico tenía carácter departamental y seguía dependiendo todavía de la cubana. El siguiente paso de Palmer, alma de toda esta organización masónica, gran maestro de la Provincial, será la creación de una gran logia soberana, independiente tanto de España como de Cuba, por completo autónoma, y autóctona, que pudiera parangonarse con las demás potencias del mundo en un plano de igualdad. Esto se consiguió también en muy poco tiempo, gracias a la generosidad de los masones cubanos, y en septiembre de 1885, quedaba instalada la Gran Logia Soberana de Libres y Aceptados Masones de Puerto Rico (GLS) con sede también en Mayagüez ${ }^{5}$.

5 En el folleto «Procedimiento para la constitución e instalación de la Gran Logia Soberana de Puerto Ricor, publicadoen Santo Domingo, 1885. 


\section{JOSÉ ANTONIO AYALA}

Paralelamente a este reconocimiento de la Gran Logia Soberana se produjo también el incremento de sus efectivos masónicos. A finales de siglo, en vísperas de la guerra colonial, el número de patentes de las logias emitidas por la Soberana había sido de 31 ,pero muchas de estas logias apenas sí habían estado en actividad unos meses, y renacían intermitentemente a veces con otros nombres, y otras habían «abatido columnas» para siempre.

Se conoce muy poco de la composición social, ideología etc. de los masones bajo obediencia de la Soberana. No existe ningún estudio serio sobre los organismos y componentes de esta masonería. En el archivo de la Gran Logia en San Juan, que hemos consultado personalmente, existe una documentación escasísima, desordenada y poco significativa en lo que se refiere al siglo XIX. No sabemos si en las propias localidades donde se ubicaron las logias puede existir documentación de otro tipo.

Mucho más abundante, y significativa, es en cambio la documentación sobre las logias de obediencia española que se conserva en el Archivo Histórico Nacional de Salamanca y algo en el Archivo Histórico Nacional de Madrid y en la Biblioteca Nacional, en el archivo «Comín Colomer».

Nuestro estudio sobre este tipo de organismos lo vamos a dividir en tres apartados: en el primero trataremos de los rasgos generales más sobresalientes de la masonería de obediencia española en Puerto Rico; en el segundo hablaremos de la situación política puertorriqueña, que tuvo sus propias características específicas, diferentes en gran medida a las de otras islas como Cuba y Filipinas; y, por último, intentaremos clarificar la postura de la masonería isleña ante el separatismo político y el cambio de soberanía.

\section{LA MASONERIA DE OBEDIENCIA ESPAÑola EN PUERTo RICO}

Cuatro obediencias españolas se extendieron por Puerto Rico entre 1871 y 1898. Las cuatro reconocieron una cierta autonomía masónica a la isla, creando altos organismos delegados -grandes logias, consejos, capítulos provinciales-en los que recaía la organización del territorio y muchas de las decisiones que era necesario tomar, máxime si tenemos en cuenta que las comunicaciones con la metrópoli no eran a veces tan fluidas como se hubiese deseado y la lejanía obstaculizaba la pronta resolución de cualquier conflicto.

Así el Gran Oriente Nacional de España (GONE) fundó en enero de 1877 el Capítulo Provincial de Puerto Rico, cuya sola denominación muestra el claro asimilismo entre las estructuras políticas -la consideración de la isla como provincia- y las masónicas; este organismo llevó una vida lánguida e intermitente y tuvo que ser reinstalado en dos ocasiones más, en 1882 y 1891, para extinguirse a principios de 1893. El Grande Oriente de España (GODE) creó a su vez en enero de 1888 una Gran Logia Regional de Puerto Rico, de efímera existencia, quizás menos de un año. Poca repercusión tuvo también una Gran Logia Provincial de Puerto Rico, constituída en 1889 por la Gran Logia Simbólica Española, del Rito de Memphis y Mizraim, de la que se tienen muy escasas noticias hasta 1892. Por último, el Gran Oriente Español (GOE) fundó en abril de 1894 un Gran Consejo Regional de Puerto Rico, con sede en San Juan, que se mantuvo activo hasta la crisis de 1896. 


\section{LA MASONERIA DE OBEDIENCIA ESPAÑOLA}

En estos altos organismos, semiautónomos, recayo de manera especial la defensa de las grandes cuestiones de la Orden, y concretamente la citada de los derechos jurisdiccionales, aunque a veces intervenía también en la cuestión alguna logia. Es curioso constatar el apoyo que se van a prestar entre sí estos organismos de obediencia española frente a la autóctona Gran Logia Soberana y, asímismo los intencionados, mal intencionados, equívocos adjetivos, con que se van a calificar entre sí ambas masonerías, que podían dar pábulo a unas diferencias políticas entre ellas.

Valga como ejemplo el manifiesto publicado por el Gran Consejo del GOE, en el «Boletín Oficial» de $1892^{6}$, en el que, entre otras cosas, se decía:

La Masonería antillana se divide en dos: una que pretende por todos los medios borrar su carácter nacional; otra que todo lo sacrificas al nobilísimo dictado de Masonería española. Aquella es la que fue a Lausana; ésta el Gr. Oriente Español y el Gr. Oriente Nacional de España que preside en Ven. h. Pantoja.

Esta diferencia se refleja en todo: en la práctica de la doctrina masónica, en la manera de trabajar y en la finalidad de los trabajos. La Masonería antillana que no forma en el Gr. Oriente Español o en el Gr. Oriente Nacional de España, tiende a separar; la de estos dos Orientes tiende a unir. La causa que éstos defienden... es, además de masónica, nacional.

Quedaba, pues, lanzada la acusación de separatista, a la masonería autóctona, y no sólo desde el punto de vista masónico, sino también político. La causa de la masonería española era una causa nacional, patriótica, según se decía. Frente a esta acusación, la GLS tachaba a su vez de «invasoras» a las obediencias peninsulares y se consideraba la única potencia legal en el territorio de la isla.

Volveremos después sobre este tema.

El empuje de las obediencias peninsulares en Puerto Rico superó en mucho a la difusión de la Soberana. Se tiene noticia cierta de la fundación por ellas de 82 organismos masónicos en las tres últimas décadas del siglo: es posible que existiesen algunos más, de principios de la década de los 70 , poco conocida, pero de la que hay algunas referencias indirectas. En todo caso, habria que añadir un 10 por 100, como máximo, a la cifra arriba indicada ${ }^{7}$.

Más insatisfactorio es el dato de los efectivos masónicos que formaron parte de dichos organismos. Hemos llegado a localizar en total 1832 nombres de iniciados en la Orden; pero la fragmentaria documentación que tenemos de muchas logias hace pensar que es posible que dicha cifra sólo supusiese entre el 60 y el 70 por 100 de los afiliados. El porcentaje puede tener una cierta validez para deducir algunos rasgos del colectivo masónico puertorriqueño, como pueden ser la preeminencia de una u otra obediencia, el mayor o menor peso de determinadas localidades o la distribución temporal, para intentar detectar los momentos de auge o crisis de la masonería peninsular en la isla.

Interesa también saber la adscripción social de los masones puertorriqueños, no tan sólo para conocer qué grupos socioprofesionales se sintieron atraídos por la ideología masónica sino también para intentar averiguar el peso social de los mismos en la vida isleña.

6 BOGOE., 15-5-1892.

7 La base de estos datos y de los que a continuación se exponen en AYALA. José Antonio: La Masonería de Obediencia española en Puerto Rico en el siglo XIX. Universidad de Murcia, 1991. 


\section{JOSÉ ANTONIO AYALA}

La cifra de partida se reduce para este aspecto un tanto. De los 1832 masones contabilizados, de sólo 1.450 , es decir el 79,14 por 100 se hace constar este dato en los cuadros lógicos.

$\mathrm{Si}$ agrupamos las diversas categorías socioprofesionales en los siete apartados que hemos considerado y justificado en otros trabajos anteriores, los resultados son los siguientes:

\begin{tabular}{lcc}
\hline \multicolumn{1}{c}{ Profesiones } & N.. absoluto & $\% s / 1.45 O$ \\
\hline Industriales y autónomos & 310 & 21,37 \\
Empleados y funcionarios & 298 & 20,55 \\
Comerciantes & 280 & 19,31 \\
Propietarios & 278 & 19,17 \\
Profesiones liberales & 147 & 10,13 \\
Militares y marinos & 86 & 5,93 \\
Obreros & 29 & 2,00 \\
Otros (estudiantes y Sras. sin profesión) & 22 & 1,51 \\
\hline
\end{tabular}

Se observa en el cuadro el predominio de las clases medias urbanas de industriales, comerciantes y la pequeña burguesía de empleados, funcionarios y autónomos. Estos tres apartados constituyen el 60 por 100 del total. En una gradación superior, quizás, están los propietarios y las profesiones liberales (médicos, farmacéuticos, abogados, etc.), con otro 30 por 100 .

El colectivo menos representativo en las logias es el de los obreros, con sólo un 2 por 100 del total.

El carácter mesocrático de la asociación masónica puertorriqueña parece claro, cualquiera que sea la combinación de grupos que se contemple. Más de un tercio de masones perteneció a la clase altoburguesa o media-alta de propietarios y profesionales, que constituían una élite social que ostentaba, de manera directa o indirecta, la autoridad local y a veces la representación política, y que, en todo caso, tenía el tiempo y el dinero para trabajar en la obra filantrópica de la masonería. Un porcentaje mayor correspondió, sin embargo, a la pequeña burguesía de profesiones autónomas o de pequeños comerciantes e industriales que, pese a su menor rango social y económico, constituían una clase media-baja, que tampoco dependía de un sueldo y que tenía la precisa autosuficiencia para vivir y permitirse dedicar una parte de sus ingresos a la asociación. Una relación entre profesiones y años, que no hemos hecho, quizás mostraría el incremento de esta pequeña burguesía en la masonería conforme avanza el siglo.

Se ha dicho que la dominación colonial española estuvo sustentada socialmente por militares, comerciantes y funcionarios o empleados de la administración de origen peninsular. Por lo que a este apartado profesional se refiere, ciertamente los comerciantes constituían el 20 por 100 de los efectivos masónicos, el porcentaje de militares y marinos no era despreciable -cerca del 6 por 100-, y al menos un 4 por 100 constan de las listas como funcionarios.

Lo que hay que dilucidar es cuantos de entre estos eran peninsulares. Una nueva variable en este juego de cifras que puede esclarecer, sin embargo, el papel del colectivo masónico en la historia de Puerto Rico. 


\section{LA MASONERIA DE OBEDIENCIA ESPAÑOLA}

Por lo que se refiere de manera simple y global a las nacionalidades de los masones puertorriqueños, las cifras-base se restringen aún más que para otros extremos ya que el dato sólo parece en los cuadros lógicos para el 36,19 por 100 del total. De ellos eran:

$\begin{array}{lr}\text { Puertorriqueños } & 69,68 \% \\ \text { Españoles peninsulares } & 22,92 \% \\ \text { Otras nacionalidades } & 7,39 \%\end{array}$

Si estos porcentajes fuesen representativos, en mayor o menor medida, del total, habria que resaltar la importancia del elemento peninsular en las logias -casi un 23 por 100 -, cuando en el panorama general de la sociedad puertorriqueña los españoles de la Península apenas sí sobrepasaban el 2 por 100 del total. Bien es verdad, por otra parte, que estamos hablando de logias de obediencia española, y, posiblemente, la masonería autóctona acogiese a bastantes menos.

Relacionando la nacionalidad -en este caso los peninsulares- con las profesiones, la primacía es para los militares, seguidos a corta distancia por los comerciantes. Ambos grupos constituían el 45 por 100 de todos los españoles afiliados a las logias, lo cual es congruente con la afirmación que hacíamos antes sobre los agentes de dominación colonial en la isla.

Las diferencias entre peninsulares y criollos eran nulas; simplemente unos habían nacido en la isla y otros no, y a veces una sola generación separaba el común origen español de ambos grupos. Sin embargo, la torpe administración española del XIX ${ }^{8}$ discriminó sin dudas a estos españoles de Ultramar y favoreció al peninsular que gozó en la isla de una serie de privilegios -oficios, destinos, confianza de las autoridades...-. Las diferencias entre ambos grupos se fueron ahondando y se gestó una cierta bipolarización entre dominadores y dominados que está en la base misma de la lucha política finisecular. La élite criolla, formada fundamentalmente por hacendados, periodistas, profesionales y algunos comerciantes, encabezó la oposición a la minoría peninsular.

\section{EL CONTEXTO POLÍTICO PUERTORRIQUEÑO}

El frustrado «grito de Lares» en Puerto Rico fue el punto de inflexión de este enfrentamiento entre peninsulares y criollos, que, aunque más débil que en otros territorios americanos (como lo demuestra el hecho mismo de su fracaso) no por ello dejará de persistir de manera más o menos soterrada hasta finales de la centuria.

Las posiciones de uno y otro grupo se encauzarán desde 1870 a través de los dos partidos legales que surgieron ese año: el Partido Liberal Reformista y el Partido Conservador, denominado también este último más tarde Partido Español Sin Condiciones o Incondicional ${ }^{9}$.

8 Sobre esta cuestión Lalinde Abadia.J.: La administración española en el siglo XIX puertorriqueño. Sevilla, Escuela de Estudios Hispanoamericanos - Secretariado de Publicaciones de la Universidad, 1980.

9 Bothwell, R.B.: Orígenes y desarrollo de los partidos políticos en Puerto Rico, 1869-1980. Puerto Rico, Edit. Edil, 1988. 


\section{JOSÉ ANTONIO AYALA}

Ambos partidos acogieron a sectores sociopolíticos diferentes: el elemento criollo nutrió las filas del Partido Liberal Reformista, mientras que el conservador o Liberal Conservador lo formaba en su totalidad, o casi totalidad, el sector peninsular. Las descalificaciones entre sí de ambos grupos menudearon: para los liberales los conservadores eran «renegados», "vendidos», «hijos espúreos», mientras que estos últimos consideran a aquellos como «antiespañoles», "socialistas», «desleales» etc. ${ }^{10}$

¿Cuál era la postura de los dos partidos ante la situación de Puerto Rico? Para el Partido Conservador, la isla formaba parte de la misma España, era una provincia más del pais, y por lo tanto ningún condicionamiento cabía hacer a la política colonial que hasta el momento regía; esta posición conservadora valió a dicho partido el apoyo de los gobernadores de la isla y de las autoridades en general. Enfrente, el Partido Liberal Reformista, se mantuvo desde su nacimiento dentro de unos límites eminentemente pragmáticos y moderados, muy alejados del radicalismo de otros grupos políticos en otros territorios. Rechazó siempre la acusación que le hacían sus contrarios de «separatista» y se confesaba abiertamente como «asimilista», esto es, partidario de la presencia de España en Puerto Rico y del reconocimiento por la metrópoli a los isleños de los mismos derechos que tenían los españoles en la Península; su programa político se asemejaba al del Partido Progresista o Fusionista español, con el que mantenía acuerdos al principio.

Sin embargo, los obstáculos que este Partido Liberal encontró dentro y fuera de la isla para conseguir sus objetivos le hizo evolucionar hacia posiciones más avanzadas que abocaron en la fundación del Partido Autonomista Puertorriqueño en 1887. Pese a algunas ambigüedades, el propósito confesado de este Partido, que se mantuvo hasta finales de siglo, era «alcanzar la mayor descentralización posible dentro de la unidad nacional» ${ }^{11}$. Es decir, lo que reivindicaban los autonomistas era pura y simplemente una mera descentralización administrativa.

La evolución del autonomismo fue muy débil y titubeante. El mismo año de su nacimiento, en 1887, experimentó de manera especial una cruel persecución por parte del gobernador de la isla, el teniente general Romualdo Palacio, afiliado a la Izquierda Dinástica española, pero a quien los informes tendenciosos de los conservadores o militares de la isla hicieron temer una segregación del territorio ${ }^{12}$. El general Palacio metió en el mismo saco de su persecución a liberales autonomistas y masones y muchas logias se vieron obligadas a suspender sus trabajos y muchos masones ingresaron en prisión acusados de conspiración.

Aunque la persecución duró sólo unos meses y el general Palacio fue destituído, su recuerdo perduró en la isla y su persecución contribuyó a debilitar al Partido Autonomista dirigido entonces por el masón Román Baldorioty de Castro, licenciado en Ciencias Físico-Matemáticas, ex-diputado a Cortes y uno de los prohombres de Puerto

10 Sobre esta rivalidad, véase Pérez Moris, J.; Cueto y GonzálezQuijano. L.: Historia de la insurrección de Lares. Río Piedras, Edit. Edil, 1975. 2. ${ }^{\mathrm{a}}$ edic. (1.9 en 1872).

11 Bothwell: Ob. cit., p. 18.

12 Pedreira, Antonio S.: Elañoterrible del 87. Susantecedentesysusconsecuencias. Río Piedras, Edit. Edil, 1974. 


\section{LA MASONERIA DE OBEDIENCIA ESPAÑOLA}

Rico. Este renunció a su cargo en 1888 y desde entonces, apenas nacido, se abrió una crisis en el Partido que se ahondó aún más en 1891, cuando dos sectores del mismo encabezados por los escritores Luis Muñoz Rivera y Manuel Fernández Juncos se enfrentaron por la cuestión de si era oportuno pactar o no con el Partido Liberal de Sagasta en la Península.

La reacción por parte del elemento criollo contra el general Palacio consistió en la creación de una sociedad secreta, que nada tuvo de masónica, denominada La boicotizadora porque inició desde entonces un boicot contra los almacenistas y comerciantes peninsulares en la isla, a los que acostumbraba a llamar los «mojados» (por referencia a la travesía marítima que hubieron de realizar para llegar a Puerto Rico) frente a los criollos o secos.

La crisis del Partido Autonomista coincidió con el auge de la asociación masónica, debido a su legalización por el decreto de 13 de junio de 1888 que hacia extensiva a Puerto Rico la Ley para el Ejercicio del Derecho de Asociación, promulgada en España un año antes.

Entre 1889 y 1897 se fundaron el 72 por 100 de todos los organismos masónicos que vieron la luz en las tres últimas décadas del siglo.

Es hora de que relacionemos los nuevos datos que hemos introducido. La pregunta inicial es: ¿en qué partidos políticos militaron los masones de obediencia española, peninsulares o criollos?

Una respuesta científica a esta pregunta sólo puede darla una comparación entre las listas de militantes de los partidos políticos puertorriqueños y las de masones. Como de estos conocemos unos 2.000 nombres, calculando quizás, no sabemos, unos 8.000 ó 10.000 de los primeros, el número de registros secuenciales que habría que hacer sería de varios millones. Algo que sólo sería factible realizar, tras ardua tarea, en un ordenador adecuado. Y el resultado no sabemos si merecía la pena, porque el que un masón pertenezca a un partido político puede tener importancia o no, según lo que aporte o deje de aportar al mismo y eso es más difícil de averiguar.

Con toda modestia, pues, y sin ánimo justificativo alguno, reconocemos esta carencia, y advertimos del relativismo de las siguientes consideraciones que vamos a hacer.

En una ojeada superficial sobre los políticos y masones puertorriqueños más destacados, resulta incuestionable que ningún partido acaparó de manera exclusiva a los masones de la isla. Hubo masones en el Partido Conservador o Incondicional y los hubo también en el Partido Liberal y después en el autonomista. Sin embargo, los ejemplos más numerosos los hemos encontrado en este último, aunque aquí no podemos dar porcentajes.

Curiosamente, los dos miembros más destacados del Partido Autonomista en los años 90 , y rivales entre sí, eran los masones Muñoz y Rivera y Fernández Juncos, a los que hemos hecho referencia más arriba.

Muñoz Rivera, presidente del Partido Liberal, era criollo (había nacido en Barranquitas) y fue destacado poeta y periodista; había sido el fundador del periódico de Ponce «La Democracia», cuyos artículos, de elevado contenido político, tuvieron un gran eco en la vida puertorriqueña. Masónicamente no destacó mucho; fue miembro de la logia Aurora de Ponce, bajo la GLS, en la que alcanzó el grado 3. de maestro. 


\section{JOSÉ ANTONIO AYALA}

Fernández Juncos era peninsular, de Asturias, aunque marchó a Puerto Rico siendo un niño. Había sido iniciado en la logia Estrella de Luquillo, de San Juan, también bajo obediencia de la GLS, si bien después, en 1884, no sabemos por qué causas, pasó a las obediencias españolas y estuvo afiliado a la logia Patria $n .{ }^{\circ} 191$ de la capital y formó parte del Capítulo Provincial de Puerto Rico y del Consejo Regional; llegó a ostentar el grado 32 de la Orden. Era también escritor de muy diversos temas, en prosa y en verso, y periodista, fundador del periódico más leído y celebrado de su tiempo, «El Buscapié». Políticamente presidía una rama disidente y minoritaria del autonomismo denominada Partido Autonomista Histórico Puro u Ortodoxo.

A finales de 1876, Muñoz Rivera llegó a un acuerdo en el balneario de Fortuna (Murcia) con el jefe del Partido Liberal Fusionista de la Península. Práxedes Mateo Sagasta, por el que este se mostraba dispuesto a aprobar, en términos generales, la autonomía que pedían los puertorriqueños. El grupo político de Muñoz Rivera pasó a denominarse Partido Liberal Fusionista Puertorriqueño, al que algún tiempo después se unía el grupo de Fernández Juncos para constituir un único Partido titulado Unión Autonomista Liberal.

El asesinato de Cánovas del Castillo y la subida al Poder de Sagasta en 1897 convirtió en realidad el pacto de los liberales españoles con los puertorriqueños. El Consejo de Ministros de 9 de noviembre de ese año aprobaba, a propuesta de Segismundo Moret, el ministro de Ultramar, tres decretos reconociendo la autonomía administrativa de Puerto Rico.

Con arreglo a los mismos, el Gobierno Autonómico puertorriqueño quedaba configurado por un Presidente y cinco Ministerios o Secretarías de Despacho y un Parlamento dividido en dos cuerpos, que eran la Cámara de Representantes y el Consejo de Administración.

El primer Gabinete Autonómico insular fue nombrado el 10 de febrero de 1898. De sus seis componente, al menos cuatro, que sepamos, eran masones: Muñoz Rivera, en Justicia y Gobernación; Fernández Juncos, en Hacienda; el presidente, Francisco Mariano Quiñones, y Manuel Rossy Calderón, en Instrucción Pública. De los cinco subsecretarios, nombrados a su vez por estos, cuatro también (del quinto hay algunas dudas) lo eran: Julián Blanco Sosa, José Celso Barbosa, Cayetano Coll y Toste y José de Diego. De los ocho masones citados, sólo tres habían pasado por logias de obediencias españolas, y el resto estaban afiliados a la masonería autóctona.

Asimismo, en la Cámara insular de Representantes figuraban significados masones: Santiago R. Palmer (el fundador de la masonería autóctona), Rafael Arrillaga (gran maestro de la GLS en 1896), el presidente de la Cámara Herminio Díaz Navarro, Salvador Carbonell Toro, José Gómez Brioso, Luis Muñoz Morales, Modesto Bird León, etc. También en esta institución el predominio correspondía a los masones encuadrados en la Gran Logia Soberana.

La simple mención de estos nombres en los más altos organismos insulares pone de manifiesto la presencia masónica en la vida política puertorriqueña y, a la par, el predominio del autonomismo criollo que, sin el recurso a la fuerza, desde postulados reformistas, había alcanzado las más altas instancias del país.

No existió, en efecto, en Puerto rico una resistencia armada al Gobierno español al estilo de la insurrección revolucionaria cubana de 1895 o de la acción de la asociación 


\section{LA MASONERIA DE OBEDIENCIA ESPAÑOLA}

secreta «Katipunam» en Filipinas. Se organizó en el exilio, en Nueva York, en 1895, una débil e inoperante Junta Revolucionaria puertorriqueña en conexión con el Partido Revolucionario Cubano, en activo en dicha ciudad. Pero la tranquilidad en la isla fue absoluta o casi absoluta; el elemento peninsular no fue hostigado en ningún momento, $y$, aún más, tropas puertorriqueñas participaron en la lucha contra los cubanos sublevados.

Se ha dicho que el régimen autonómico llegó tardíamente a Cuba, en donde dicha fórmula intermedia se vio arrollada por la revolución separatista; pero, en Puerto Rico, la autonomía de 1898 podía haber cuajado con el tiempo en una emancipación sin traumas, sin giros bruscos ${ }^{13}$, porque en esta isla el Partido Autonomista, el más avanzado del país, y la única fuerza organizada, había dado pruebas fehacientes de responsabilidad y de flexibilidad respecto a la postura española.

Nada de esto pudo ser. Los cuerpos legislativos insulares se reunieron por primera vez el 19 de julio de 1898 y el 25 de ese mismo mes las tropas norteamericanas invadieron la isla, con lo cual quedaron paralizados todos los trabajos gubernamentales y legislativos, apenas puestos en marcha. Unos días después, el 12 de agosto, se firmaba en Washington el Protocolo de Armisticio entre España y Estados Unidos, ratificado más tarde el 10 de diciembre por la Paz de París.

Puerto Rico, que en principio nada tenía que ver con el contencioso hispanoamericano en el Caribe, centrado en la isla de Cuba, era cedido incondicionalmente a los Estados Unidos como botín de guerra, por los gastos que ésta había ocasionado al pueblo americano.

La independencia -o mejor, el cambio de soberanía- de Puerto Rico, se debió a una causa externa, sin conexión alguna con la situación interior de la isla, y por lo tanto apenas sí tiene sentido que nos planteemos si tal grupo puertorriqueño o tal otro era más o menos proclive al separatismo. No hubo lucha de ideas, ni siquiera el más mínimo respeto por parte de Estados Unidos al Derecho Internacional, sino que fueron las armas el único argumento empleado por los vecinos del norte ${ }^{14}$.

La masonería -o masonerías- puertorriqueñas, como otros grupos insulares, no fue parte activa en el conflicto, y éste le cogió no sólo desprevenida sino además, como veremos, desorganizada. Pero una reflexión sobre su postura al respecto -aunque pueda tener el carácter de mero futurible, desbordado por los hechos- no será ociosa por completo y puede tener su interés.

\section{MASONERIA Y SEPARATISMO}

Tradicionalmente, la institución masónica en general -y la puertorriqueña no era una excepción- había proclamado su apoliticismo como tal institución, aunque sus miembros, sin embargo, a título individual, como hombres libres que eran, podían formar parte de los diversos partidos políticos y era aconsejable que participaran en la vida pública.

13 Gautier Dapena, José A.: Trayectoria del pensamiento liberal puertorriqueño en el siglo XIX. San Juan de P. R., Instituto de Cultura Puertorriqueña, 1963, p. 77.

14 Azcárate, Pablo de: La guerra del 98. Madrid, Alianza Edit., 1968, p. 202. 


\section{JOSÉ ANTONIO AYALA}

Pero esta opción política de los masones tenía un límite: que no se opusiese a los principios éticos y filosóficos de la masonería, que fuese, cuando menos, tolerante como la misma institución con las diferentes opiniones, o, lo que es lo mismo en política, que fuese una opción democrática. La vinculación masónica con el liberalismo venía de lejos porque sólo en regímenes de este tipo la asociación había sido respetada, tolerada y había podido difundir sus principios.

La aplicación de esta doctrina se llevó a cabo con rigor en Puerto Rico. Algunos reglamentos de logias y otros organismos especificaban de forma clara la prohibición de tratar temas políticos y religiosos en sus sesiones. Hubo masones en el partido conservador y los hubo también, creemos que en mayor número, en el Partido Liberal Reformista y después en el Autonomista Puertorriqueño.

Ahora bien, el liberalismo sin duda tiene un componente individual de origen -la autonomía del individuo frente a los poderes públicos-, pero conforme avanzó el siglo, por influencia sobre todo del marxismo, el concepto se amplió a aspectos de carácter social y de autonomía de los pueblos, especialmente de los territorios coloniales, frente a todo dominio extranjero. Resultaba cuando menos contradictoria la libertad del individuo en un territorio sojuzgado por otra nación.

Esta contradicción teórica se produjo también en la masonería establecida en territorios coloniales. La realización del hombre en libertad para su propio perfeccionamiento, ¿era compatible con el dominio que la metrópoli ejercía en la colonia? ¿Se podía ser plenamente libre en un territorio que no lo era?

Una forma de soslayar la cuestión era, como hizo España, considerar a las colonias como una parte del propio solar peninsular, como provincias españolas. Pero ni étnica ni políticamente ello era cierto, aparte de la extensa vaguada -con agua incluida- que existía entre Europa y América. De todas maneras la idea fue creída interesadamente por los gobiernos españoles y practicada también- por una asimilación nacionalista- por los masones españoles, que pusieron su empeño en formar individuos con un máximo de racionalidad y el mayor progresismo ideológico, y al mismo tiempo defendieron la vinculación de Puerto Rico a España.

En efecto, en las logias puertorriqueñas de obediencia española, los testimonios son frecuentes sobre el derecho de España a gobernar ese territorio y la oposición a cualquier separatismo.

Así la logia Hijos de Borinquen n. 146, de San Germán, decía en una de sus misivas al Gran Consejo:

En nuestra agrupación masónica no hay ningún hermano rebelde ni desafecto a la causa de España, sino que todos somos buenos hijos y españoles ante todo, como gustosos lo probaríamos ${ }^{15}$.

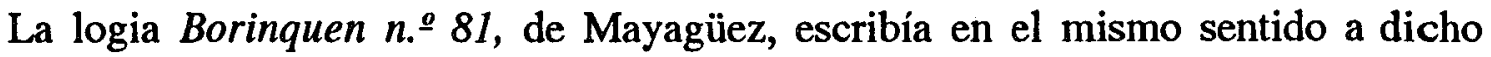
organismo:

... podemos responder de las Logias de obediencia del Gr. Or. Español, que siempre han dado pruebas de lealtad, respeto y cariño a la Patria ${ }^{16}$.

15 AHNS. Sec. Mas., leg. 363-A. exp. 6.

16 AHNS. Sec. Mas., leg. 253-A. exp. 1. 


\section{LA MASONERIA DE OBEDIENCIA ESPAÑOLA}

La logia Legalidad Espñola n.` 67, de Guayana, insistía en la misma idea patriótica:

En este apartado rincón de la patria española, existe un puñado de hermanos dispuestos siempre a derramar por ella la última gota de sangre... ${ }^{17}$.

El «Boletín de Procedimientos» de la Gran Logia Simbólica, del Rito de Memphis, obediencia de confesado republicanismo que contaba con cinco logias en Puerto Rico, arremetía también en 1894 contra todo separatismo, aludiendo en especial al cubano, en un editorial titulado «Patria y Masonería» en el que pedía a todos sus afiliados «guerra sin cuartel al separatista» ${ }^{18}$.

Por último, el manifiesto publicado por el Gran Consejo del GOE en 1892, al que hacíamos referencia en páginas anteriores, reivindicaba para la masonería de obediencia española -tanto el Gran Oriente Español como el Gran Oriente Nacional de España- la defensa de una causa «además de masónica, nacional» ${ }^{19}$.

La idea separatista, pues, no parece que tuviese ningún predicamento en las logias, cuya neutralidad política era innegable y que además tenían clara la consigna recibida por los más altos organismos de la Orden en ese sentido. La masonería de obediencia española se confesaba nacionalista en ese aspecto y por lo tanto opuesta en todo lo que pudiera significar segregación territorial de las islas. $\mathrm{Y}$, aún más, hay algún indicio suelto, que no podemos generalizar, no sólo de la reluctancia al tema separatista sino de la positiva lucha de la asociación por mantener la soberania española en Puerto Rico.

En diciembre de 1890, el secretario de la logia Legalidad Española n. ${ }^{\circ} 67$, el gallego Urbano Pérez Rodríguez, que había fundado tres logias en la isla, se dirigía al Gran Consejo de Madrid en estos términos:

La Masonería en este país -decía- es considerada como atentatoria a nuestra Nacionalidad Española, y en verdad y que para contrarrestar parte de estos efectos levantáronse Talleres Españoles bajo la Obediencia del Gr. Or. Español teniendo que vencer dificultades de consideración, pero como mi Patriotismo no admitía duda conseguí en buena hora buen resultado 20 .

En este texto, pues - no sabemos en qué medida cierto- se presenta al Gran Oriente Español como contrapeso a otras tendencias separatistas existentes en la masonería, de hecho como un «agente español» o españolista que luchaba por la dominación española de la isla. Aunque esta idea es posible que no fuese compartida por otros masones o logias, sin duda debía tener un cierto arraigo entre los grupos peninsulares afiliados a algunas de ellas.

Frente a esta masonería españolista es posible que coexistiera otro tipo de masonería - la autóctona de la Gran Logia Soberana- menos apegada a la causa nacionalista y al dominio colonial. Alguna logia de organización española -y como hemos visto incluso

17 AHNS. Sec. Mas., leg. 272-A, exp. 1.

18 «Boletín de Procedimientos del GCGI», 28-2-1894.

19 BOGOE, 15-5-1892.

20 AHNS. Sec. Mas., leg. 272-A, exp. 1. 


\section{JOSÉ ANTONIO AYALA}

el Gran Consejo del GOE- no dudaba en acusar a las logias de la Gran Logia Soberana de separatistas, aunque no sabemos si con una cierta exageración, dada la rivalidad territorial existente. Así, la logia Borinquen $n . \stackrel{\circ}{81}$, de Mayagüez, informaba en abri1 de 1892, al Gran Consejo:

Existe aquí una masonerla irregular, titulada de Puerto Rico, que no es otra cosa que una hija bastarda de la de «Colón» con todo su filibusterismo. Esta masonería no practica más nada de la Orden general, que la beneficencia; en lo demás, es puramente una asociación separatista... ${ }^{21}$.

La cuestión necesitaría más comprobaciones. Desde luego, los más altos dirigentes de la masonería autóctona no ocultaban su partidismo por la autonomía isleña; pero ya sabemos el carácter reformista y mesurado que adoptó esta opción política en Puerto Rico. El padre de la masonería autóctona, Santiago R. Palmer, gran maestro de 1885 a 1888 fue uno de los fundadores del Partido Liberal Reformista primero, y del Partido Autonomista después; en su estancia en Norteamérica de 1892 a 1896 simpatizó y tuvo contactos con el Partido Revolucionario Cubano de Nueva York. El gran maestro de 1889, Rosendo Marienzo Cintron, fue también un Caudillo del Partido Autonomista y convencido republicano. Las mismas ideas políticas sustentaba el farmacéutico de Añasco Rafael Arrillaga, gran maestro de 1894 a 1898.

De todas formas, cualesquiera que hubieran podido ser las posturas masónicas ante la cuestión colonial -más o menos españolistas o segregacionistas-, una circunstancia, en parte también externa, contribuyó a hacer por completo inoperante cualquier activismo en esa dirección: la crisis masónica de 1896.

En ese año, como se sabe, los sucesos masónicos de Madrid, que llevaron a la clausura de las sedes de los grandes orientes, y los de Filipinas, con el descubrimiento de sociedades secretas separatistas, repercutieron en Puerto Rico, sin causa alguna que lo justificase. La tranquilidad en esta isla era completa, parte de su guarnición incluso luchaba contra los insurrectos cubanos y la masonería estaba legalizada y no había hecho manifestación política de ningún tipo. Pese a todo ello, y más con ánimo preventivo que represivo, el gobernador general de la isla, Sabas Marín González, publicó una circular el 9 de diciembre de 1896 en la que ordenaba la clausura de todas las logias masónicas.

La disposición de todas las logias puertorriqueñas, sin acepción de organizaciones, ante la circular fue de completa obediencia a lo ordenado, pese a lo arbitrario e ilegal de la medida. El ejemplo lo dio precisamente la Gran Logia Soberana en su última reunión de 27 de diciembre de 1896 en la que acordó por unanimidad, para sí y para todos sus organismos:

... suspender por ahora los trabajos a fin de que no pueda sospecharse ni aún remotamente de una institución que es enteramente ajena a la política...22.

21 AHNS. Sec. Mas., leg. 253-a, exp. 1.

22 Reproducción del acta de la GLS, en el «Boletín Oficial de la Gran Logia Soberana de Puerto Rico», n. 96 , de 15 de junio de 1912 . 


\section{LA MASONERIA DE OBEDIENCIA ESPAÑOLA}

Las logias de obediencia española también acataron la orden, aunque alguna elevó su protesta al Gran Consejo por lo que consideraba una vulneración de sus derechos de asociación. Las autoridades de la isla hicieron, sin embargo, una excepción discriminatoria con la logia Palafox n. 174, de San Juan, bajo el GOE, y su capítulo Rosa Cruz Lanuza, según las propias fuentes masónicas debido a que ambos organismos, compuestos por «Jefes y Oficiales del Ejército, no podían serle sospechosos» ${ }^{23}$.

La razón de la tolerancia de dicha logia debió ser otra, porque hemos examinado los cuadros lógicos de 1896 y 1899, que se conservan, uno con 52 miembros y otro con 36, y en el primero sólo aparecían 4 militares y en el segundo 3 marinos. Más probable parece que la autorización de la Palafox se debiese a algún valedor importante ante las autoridades o bien al buen número de peninsulares que formaban parte de su cuadro, 17 en total, lo cual explicaba la confianza que inspiraban los trabajos de este taller.

A lo largo, pues, de casi un bienio, el de 1897-98, la masonería de cualquier obediencia -salvo los organismos citados más arriba- interrumpió toda actividad en Puerto Rico. Vigilados sus miembros por la policía, desarticulados sus organismos y cerrados sus talleres mal podían los masones puertorriqueños prestar ningún tipo de concurso a cualquier movimiento separatista, suponiendo que existiese dicho movimiento y que la ideología masónica lo aceptase.

Cuando se reanuden las actividades masónicas, de forma incipiente desde mediados de 1898, el Gran Oriente Español, la potencia hegemónica en años anteriores en Puerto Rico, pasaba por unos de los peores momentos de su historia y ello fue aprovechado por la autóctona Gran Logia Soberana para tomar la delantera de la reorganización de sus efectivos. El apoyo, oportunista, de esta masonería al nuevo régimen norteamericano le granjeará la tutela, también en este aspecto, de su vecino del Norte, de cuyo Supremo Consejo del Sur, con sede en Charleston, pasó a depender, aunque la Gran Logia Soberana de Puerto Rico conservaba la autonomía para la organización de la masonería simbólica.

La masoneria de obediencia española, si exceptuamos de nuevo a la logia Palafox y a su capítulo Lanuza, no reanudará sus actividades en Puerto Rico hasta 1903. Desde entonces irá incrementando sus efectivos en la isla, en competencia, como en años anteriores, con la GLS, pero ya en circunstancias históricas diferentes que constituyen un nuevo período o etapa de la historia de esta institución.

Paradójicamente, en esta nueva etapa, los antiguos dominados se considerarán vencedores (aunque sólo habían cambiado de soberanía) y con derecho al territorio, y los españolistas -peninsulares, sobre todo, que seguirán formando parte de las logiasse negarán ahora a reconocer un poder que se ha impuesto por la fuerza y que, según el tratado de París, sólo afectaba a la soberanía pero no a las asociaciones existentes en la isla. Esta es, pues, otra historia con diferentes factores.

23 «Boletín Oficial y Revista Masónica de la Gr. Log. Regional de Puerto Rico», n.. 4, 15 de junio de 1913. 


\section{JOSÉ ANTONIO AYALA}

\section{RECAPITULACIÓN FINAL}

Los factores que hemos manejado en esta exposición, constituyen, desde diversas perspectivas, un pequeño puzzle cuyos elementos componen, creemos, un cuadro integrado de lo que fue la masonería puertorriqueña en el siglo XIX y del papel que jugó ante el conflicto colonial, que era nuestro tema.

En primer lugar, estamos ante una masonería numerosa y plural: unos 120 organismos entre 1871 y 1898 , pertenecientes a varias obediencias españolas y a la autóctona Gran Logia Soberana. No debemos olvidar, sin embargo, que el peso de las primeras es tres veces superior al de esta última Gran Logia.

En segundo lugar, es una masonería, desde el punto de vista social, predominantemente mesocrática, y, en este sentido, pocas diferencias pudiéramos establecer con la existente en la España de la época.

Pero, la variedad etnológica de la isla sí que es un elemento a tener en cuenta, especialmente en la confrontación más que étnica social que se produce entre la minoría peninsular y la mayoría criolla. En este aspecto, la detección de un fuerte componente de peninsulares en las logias de obediencia española -no sabemos si también en las de la GLS, aunque creemos que no- es significativa por cuanto hay que suponer unas actitudes más o menos españolistas en este grupo masónico.

Los dos partidos legales a través de los cuales se encauzaron desde 1870 estas actitudes -el Conservador Incondicional y el Liberal Reformista o Autonomistarepresentaron, por un lado, a ese sector españolista, y por otro a un sector más avanzado liberal, y después autonomista, pero que en ningún momento adoptó posiciones revolucionarias que hiciesen peligrar el dominio de la isla por España.

La masonería, dessde su tradicional apoliticismo institucional, dejó en libertad a sus miembros para que se alinearan en uno u otro partido, y hay constancia de que este pluralismo político se respetó, si bien una mayoría de los mismos parece que militó en el liberalismo autonomista. Prueba de ello es que cuando se constituyó el primer Gabinete Autonómico en 1898 casi todos sus componentes eran masones, y de éstos, la mayoría, afiliados a la Gran Logia Soberana.

Parece meridianamente claro, por otra parte, que la masonería de obediencia española nada tuvo que ver con la idea y el hecho separatista, por tres razones, principalmente: 1. a , porque la corriente nacionalista -de «integración nacional» de la isla- era bastante fuerte en sus filas y entre los altos organismos directivos; $2 .{ }^{\mathrm{a}}$, porque el separatismo apenas sí tuvo fuerza en Puerto Rico, a diferencia de otras islas, y la masonería no fue una excepción a este contexto social; y, en tercer lugar, por el hecho objetivo de que cuando surge el conflicto colonial en 1898 las obediencias masónicas puertorriqueñas, sin excepciones, atravesaban una crisis desde 1896, que había dispersado sus efectivos y que las invalidaba para cualquier acción, o siquiera corriente de opinión.

Por último, otro factor objetivo, que anula cualquier positiva idea o acción segregacionista, masónica o no masónica, es que el cambio de soberanía de Puerto Rico se debió a una causa externa sin conexión con la situación interior de la isla: la intervención, por la fuerza, de Estados Unidos. 